\title{
Photodegradation of Unmodified and Thermally Modified Wood Due to Indoor Lighting
}

\author{
Dace Cirule ${ }^{1, *}$, Edgars Kuka ${ }^{1,2}$, Matiss Kevers ${ }^{1}$, Ingeborga Andersone ${ }^{1}$ and Bruno Andersons ${ }^{1}$ \\ 1 Latvian State Institute of Wood Chemistry, Dzerbenes 27, LV-1006 Riga, Latvia; edgars.kuka@kki.lv (E.K.); \\ matisskevers@gmail.com (M.K.); i.andersone@edi.lv (I.A.); bruno.andersons@edi.lv (B.A.) \\ 2 Faculty of Material Scuience and Applied Chemistry, Riga Technical University, Paula Valdena 3, \\ LV-1048 Riga, Latvia \\ * Correspondence: dace.cirule@kki.lv
}

Citation: Cirule, D.; Kuka, E.; Kevers, M.; Andersone, I.; Andersons, B.

Photodegradation of Unmodified and Thermally Modified Wood Due to Indoor Lighting. Forests 2021, 12, 1060 https://doi.org/10.3390/f12081060

\section{Academic Editors:}

Carmen-Mihaela Popescu and Holger Militz

Received: 28 June 2021

Accepted: 3 August 2021

Published: 9 August 2021

Publisher's Note: MDPI stays neutral with regard to jurisdictional claims in published maps and institutional affiliations.

Copyright: (c) 2021 by the authors. Licensee MDPI, Basel, Switzerland. This article is an open access article distributed under the terms and conditions of the Creative Commons Attribution (CC BY) license (https:/ / creativecommons.org/licenses/by/ $4.0 /)$.

\begin{abstract}
Considering interior applications, sunlight, both direct through open window and through window glass, and artificial lighting are the main sources of radiation possessing sufficient energy to trigger photodegradation processes in wood. LED lamps, which emit mostly visible light, are becoming the dominant artificial light source in various interiors. In the present study, photodegradation of thermally modified (TM) and unmodified (UM) ash (Fraxinus excelsior), aspen (Populus tremula), and pine (Pinus sylvestris) due to exposure to UV radiation and LED lamps was evaluated and compared by analysing wood discolouration (CIELAB colour space), changes in reflectance and FTIR spectra, and formation of water-soluble components. The results show that, apart from UV radiation, LED lamps may cause considerable photodegradation of both TM and UM wood resulting in visually perceptible colour change, alteration in chemical structure and formation of water-soluble components. Improved photo-stability was observed for TM wood exposed to UV radiation, while even more changes in FTIR spectra were detected for TM than UM wood in the experiment with LED lamps. Comparing TM and UM wood, the changes due to photodegradation were quite similar for TM wood of all species while significant differences were observed in the case of UM wood.
\end{abstract}

Keywords: wood discolouration; wood photodegradation; thermally modified wood; UV; LED

\section{Introduction}

Thermal modification has become a well-commercialized process throughout the world, being mainly used to provide wood with improved dimensional stability and resistance to decay [1-5]. However, the inherent lighter or darker brown colour is often regarded as another important characteristic of thermally modified (TM) wood that facilitates consumers' preference [6-8]. It is also suggested that, due to the colour similarity, TM wood could be used as a substitute for some tropical woods which would be favourable for reducing the over-exploitation of tropical forests $[9,10]$. Although research results related to outdoor applications dominate in the literature, it is stated that TM wood can be used as well indoors for floorings, decorative panels, kitchen and bathroom furniture, stairs, etc. $[2,4,9,11-13]$. For interior applications, stability of aesthetic appearance is of especial importance and discolouration is a serious problem from the viewpoint of commercial worth of a material [14]. Reliable information on the colour stability and changes in appearance that can be expected is an essential issue for increasing awareness of the use of TM wood in interiors.

The colour of any material depends on its chemical composition, namely, a combination of chromophores that absorb certain wavelengths of the visible light in such a way altering the spectral composition of the reflected radiation, which, when entering the human eye, creates a sense of definite colour. Therefore, the reflection curve in the visible light region is an accurate representation of the colour of a material [14]. However, the most widely employed method for analysing the colour of wood, which allows quantification of 
changes in colour caused by different stimuli, is characterization of the colour by using the colour parameters $\left(\mathrm{L}^{*}, \mathrm{a}^{*}, \mathrm{~b}^{*}\right)$ of the CIELAB colour space [11].

Wood darkening is an unavoidable effect of thermal modification which implies that, among other chemical transformations, new chromophores are generated in wood during heat treatment. The tonality of the new colour depends on both the wood and treatment characteristics. In general, progressive wood darkening with increasing treatment temperature and duration has been observed $[2,15,16]$. Another factor promoting greater colour alteration is presence of oxygen instead of inert atmosphere in the thermal modification process $[7,17]$. Different possible chemical reasons of wood darkening due to TM have been proposed in the literature including formation of quinones $[17,18]$, degradation products from hemicelluloses, extractives, and lignin [8,19], condensation and oxidation reaction [17]. Since most of the chromophoric substances of TM wood cannot be extracted, it is suggested that they are of high molecular mass and degree of cross-linking [7]. However, the chemical reactions that occur during thermal modification and are related to wood colour change are still far from being completely understood.

Wood is known to be vulnerable to photodegradation when exposed to irradiation. In the case of wood, apart from UV radiation, which is well acknowledged to be the dominant cause of wood photodegradation, shorter wavelengths of the visible light have been found to cause photodegradation as well [14,20-22]. It is well established that discolouration is the most sensitive indicator of wood photodegradation which appears even before conclusive chemical changes can be observed [20]. Lignin is acknowledged to be the key structure involved in wood photodegradation. Lignin contains many chromophoric structures and is the only of the wood main constituents absorbing relatively strongly in the UV and shorter wavelength region of the visible light [17,23-26]. Apart from lignin, phenolic extractives also can absorb in this region suggesting that they may as well be involved in the wood photodegradation. On the other hand, extractives can also exert protecting effect by absorbing the hazardous radiation and retarding photodegradation of lignin $[17,27-30]$.

Considering TM wood, the main focus has been on establishing photodegradation caused by solely UV radiation or synergistic effects of solar radiation and precipitations causing wood weathering during real or simulated outdoor exposure. Lighter or darker brown colour of TM wood indicates on substantial absorption in the whole visible light region which is also demonstrated by absorption spectra $[7,17]$. Absorption of radiation by the substrate is a prerequisite for the initiation of any photodegradation reaction. However, the absorbed radiation has to possess sufficient energy to trigger chemical transformations rather than excite only some chemical structures which are inactivated back to the ground state by converting the excitation energy into infrared radiation without causing any chemical changes in the irradiated substrate. It has been found that substantial photodegradation of TM wood was caused by the visible light of far longer wavelength (at least up to 600 $\mathrm{nm}$ ) than the wavelength range known to be hazardous for unmodified (UM) wood [22]. In general, it has been found that TM does not render to wood proper resistance against photodegradation especially for long term exposure. Conflicting results are provided in the literature on the discolouration of TM wood due to photo degradation, indicating both an improvement and a decrease in photo stability caused by TM $[6,12,23,26,31,32]$. It is also found that colour stability of TM wood depends on both the wood species and the treatment temperature $[9,12,33]$. FTIR spectroscopy is used extensively to analyse chemical changes in wood resulting from the photodegradation. When changes in UM and TM wood are compared, results contradict regarding the wood type (TM or UM) that suffers greater changes, but it is unanimously recognized that both wood types are similar in respect to the chemical groups undergoing transformations detectable by FTIR $[9,22,26,31]$.

Considering interior applications, sunlight, both direct through open window and through window glass, and artificial lighting are the main sources of radiation possessing sufficient energy to trigger photodegradation processes in wood. A number of studies have analysed various aspects of wood photodegradation caused by solar radiation while there 
is lack of knowledge about potential transformations of wood surface due to exposure to artificial light.

Today, LED lamps, due to their superior efficacy and long lifetime, are becoming the dominant light source in various interiors. Although the LED lamps emit hardly any radiation in the UV range, they typically emanate quite a lot of visible light of the shorter wavelength, which can cause wood photodegradation.

The present study is a part of the research aimed at evaluating photodegradation and providing discolouration models of different wood species depending on the light source of the incident radiation. Effect of exposure to UV radiation and LED lamps on changes in colour and chemical composition of UM and TM aspen, ash, and pine wood are analysed and compared.

\section{Materials and Methods}

\subsection{Material}

In the research, three wood species were used: ash (Fraxinus excelsior L.), aspen (Populus tremula L.), and pine (Pinus sylvestris L.). The marks used for the species throughout the research in the figures are " $\mathrm{F}$ " for ash, " $\mathrm{A}$ " for aspen, and " $\mathrm{P}$ " for pine. The boards were sourced from a local sawmill and conditioned $\left(\mathrm{RH} 65 \%, 20^{\circ} \mathrm{C}\right)$ for at least one month before further treatment. TM was carried out in a WTT (Wood Thermal Treatment, Denmark) laboratory multifunctional wood treatment device. Boards measuring $1000 \times 100 \times 25 \mathrm{~mm}$ were treated at $170{ }^{\circ} \mathrm{C}$ for $1 \mathrm{~h}$ in a water vapour medium under elevated pressure $(0.8 \mathrm{MPa})$. Three UM and TM boards of each wood species were used to prepare specimens for irradiation experiments. Two specimens measuring $150 \times 70 \times 15 \mathrm{~mm}$ for exposure to UV and two specimens measuring $70 \times 70 \times 15 \mathrm{~mm}$ for exposure to LEDs were prepared from each board. A total of four specimen sets (UM_UV, UM_LED, TM_UV, TM_LED) were prepared for irradiation experiments, each containing six specimens for each species. Three specimens measuring $10 \times 10 \times 2 \mathrm{~mm}$ were prepared from the tangential surface of each board for evaluating chemical transformations by FTIR spectroscopy. One specimen per board was exposed to UV irradiation, one to LED lamps, and one was used as a control. Pieces of similar volume from the same boards used for preparing specimens for irradiation tests were ground to obtain particles for extraction/irradiation experiments. The ground particles were fractionated by sieving and the fraction of $0.2-0.4 \mathrm{~mm}$ was used for extraction. Prior to further testing, all specimens were conditioned for one month in the dark $\left(\mathrm{RH} 65 \%, 20^{\circ} \mathrm{C}\right)$. In preliminary experiments, one month was assessed as sufficient time for ceasing of the main oxidation reactions, which are unavoidable on the freshly exposed wood surface.

\subsection{Irradiation of Specimens}

The exposure of specimens to UV radiation was carried out in an artificial weathering chamber Q-Lab (Westlake, OH, USA) equipped with fluorescent lamps of UVA-340 type. The total irradiation dose on the surface of the specimens was $8.6 \mathrm{kWh} / \mathrm{m}^{2}$. The exposure of specimens to LED lamps was carried out in chambers specially designed for this experiment (Figure 1a). The chambers were equipped with LED lamps of colour temperature $3000 \mathrm{~K}$ and the spectral composition of the emitted light is provided in Figure $1 \mathrm{~b}$. 


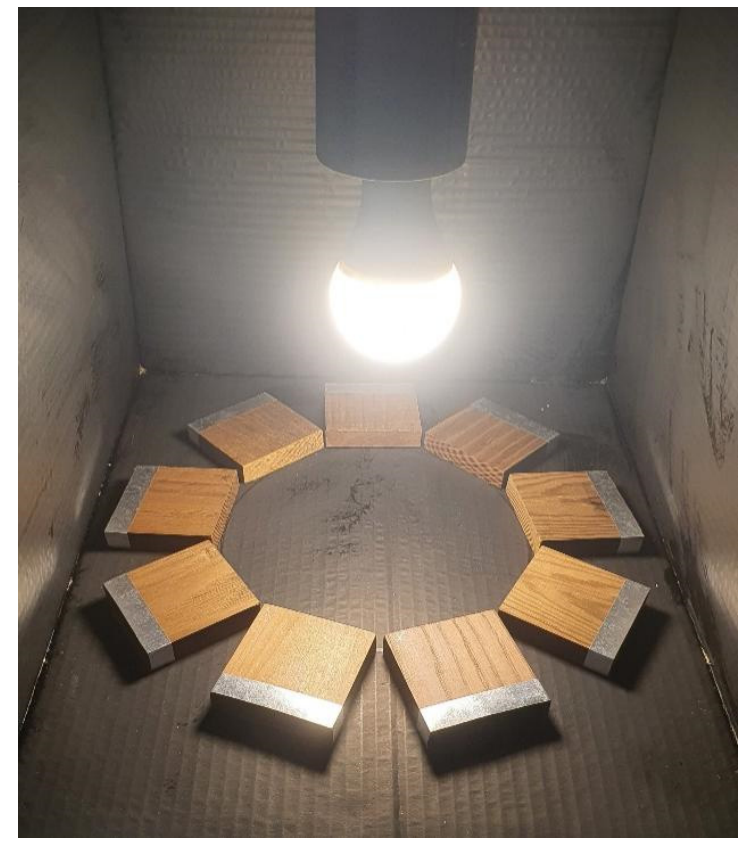

(a)

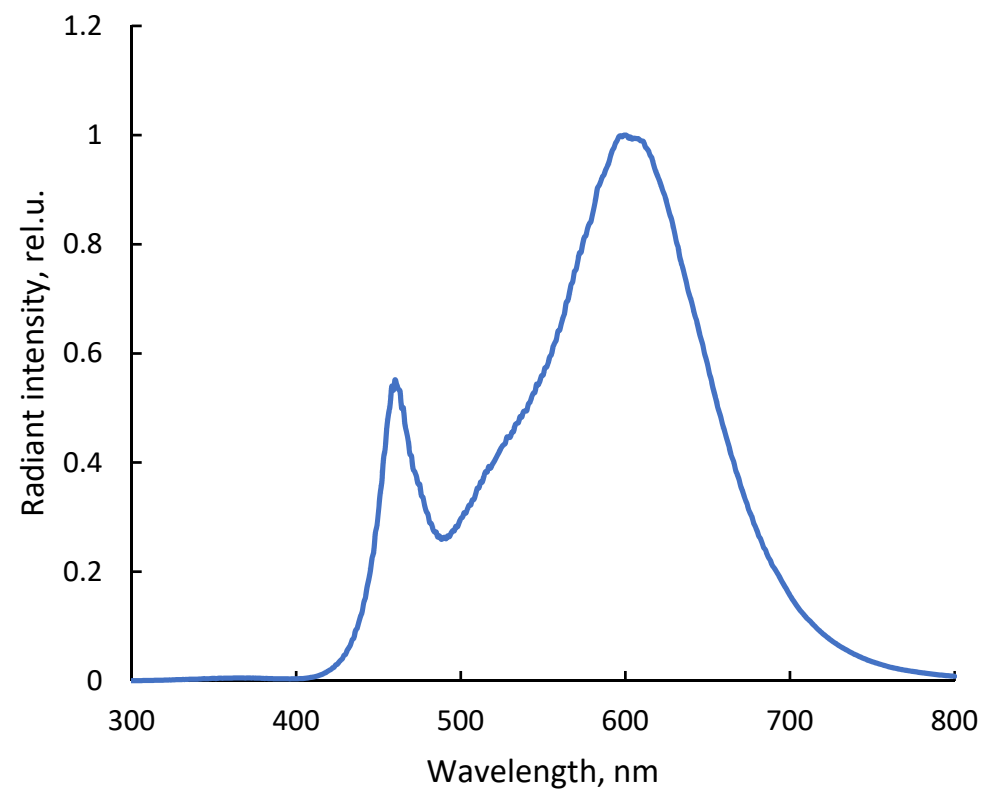

(b)

Figure 1. Chamber for exposure to LED lamps (a) and spectral composition of the LED lamps used in the experiments (b).

All walls of the chamber were coloured black to avoid additional irradiation of the specimens with reflected light of unknown spectral composition. The total irradiation dose on the surface of specimens was 3.6 Mlx h. The specimens used for evaluating changes in colour and reflectance were periodically removed from the UV and LED chambers for spectrophotometric measurements. The specimens used for assessment of changes in FTIR spectra and formation of extractable substances were analysed after exposure to the respective total irradiation doses.

\subsection{Evaluation of Discolouration}

A portable spectrophotometer CM-26dG Konica Minolta (Tokyo, Japan) (standard illuminant D65, $\mathrm{d} / 8^{\circ}$ measuring geometry, $10^{\circ}$ standard observer, measuring area $\varnothing 8 \mathrm{~mm}$ ) was used for wood reflectance spectra and colour measurements. Reflectance spectra were recorded for wavelengths ranging from 360 to $740 \mathrm{~nm}$, using a scanning interval of $10 \mathrm{~nm}$. Colour was expressed according to the CIELAB colour space (Commission Internationale de $l^{\prime}$ Eclairage 1976) as colour parameters $L^{*}, a *, b *$ The total colour change $(\Delta E a b)$ was calculated from the colour parameter differences between the initial and resulting values $\Delta \mathrm{L}^{*}, \Delta \mathrm{a}^{*}, \Delta \mathrm{b}^{*}$ according to the formula:

$$
\Delta \mathrm{Eab}=\left(\left(\Delta \mathrm{L}^{*}\right)^{2}+\left(\Delta \mathrm{a}^{*}\right)^{2}+\left(\Delta \mathrm{b}^{*}\right)^{2}\right)^{\frac{1}{2}}
$$

Spectrophotometric measurements were always recorded the same five marked points of each specimen and the average values were calculated for colour representation.

\subsection{FTIR Spectroscopy}

The irradiation doses for the FTIR specimens were equal to the total doses used in the discolouration experiments (see Section 2.2). FTIR spectra were acquired using FTIR spectrometer Nicolet iS50 (Thermo Fisher Scientific, Waltham, MA, USA) equipped with an attenuated total reflection accessory (ATR) with a diamond crystal. The scanning range was from $400 \mathrm{~cm}^{-1}$ to $4000 \mathrm{~cm}^{-1}$ and 32 scans were taken for each spectrum with the resolution of $4 \mathrm{~cm}^{-1}$. Measurements were performed at two locations per specimen. For the further analysis, the fingerprint region from $800 \mathrm{~cm}^{-1}$ to $1800 \mathrm{~cm}^{-1}$ was used. The spectra were 
pre-processed by three-point baseline correction and normalization to absorbance unit 1 for the highest absorption peak around $1030 \mathrm{~cm}^{-1}$, which is considered to be less affected by photodegradation and commonly used therefore in other studies for the same purpose, e.g., $[17,24,26,34]$. Origin software was used for the pre-processing of the spectra.

\subsection{Evaluation of Formation of Water-Soluble Substances}

Like all other specimens, the ground specimens were stored in the dark until the extraction and exposure to irradiation. Successive extraction with hot water and acetone was performed to prepare extractive-free specimens. To simulate photodegradation of wood surface, extracted and non-extracted wood particles were evenly scattered on glass Petri plates in one layer creating a wood layer of average thickness of $0.35 \mathrm{~mm}$ that was assessed to be the average diameter of the particles. The plates were exposed to irradiation with UV fluorescent lamps and LED lamps. The irradiation doses were equal to the total doses used in the discolouration experiments (see Section 2.2). After irradiation, the specimens of wood particles were extracted with hot water to determine the content of water-soluble components generated due to photodegradation. The water extracts were scanned with UV-Vis spectrophotometer PerkinElmer Lambda (Waltham, MA, USA) 650 equipped with $150 \mathrm{~mm}$ integrating sphere at a $2 \mathrm{~nm}$ interval over the wavelength range 190-700 $\mathrm{nm}$ in a quartz cuvette of $10 \mathrm{~mm}$ path length with water used as the reference blank. The spectra were normalized for $1 \mathrm{~g}$ of wood particles subjected to extraction. The difference spectra were calculated by subtracting the initial data of reflectance from the data of the irradiated specimen.

\section{Results and Discussion}

The most significant change that occurs with sunlight as it passes through the window glass is that the glass blocks most of the shorter waves of UV radiation. In preliminary experiments, specimens were exposed to two types of UVA lamps one of which simulated UV part of direct sunlight (UVA-340) while the other simulated UV through window glass (UVA-351). The intensity of the incident radiation $\left(\mathrm{W} / \mathrm{m}^{2}\right)$ on the wood surface was adjusted to be similar for both types of lamps. The results showed that the general pattern of wood colour change was similar for both types of lamps with the only difference of slower discolouration of the specimens exposed to the UVA-351 lamps during the initial period of exposure. Therefore, only UVA-340 lamps were used in the further experiments for representing exposure to sunlight and evaluating wood photodegradation due to such exposure. Similar trend was also observed when the effect of the LED lamps of different colour temperatures ( $3000 \mathrm{~K}$ and $6500 \mathrm{~K}$ ) and consequently different spectral compositions were examined in the preliminary experiments. Higher discolouration was detected for the specimens exposed to the cool LED lamps (6500 K) only for low irradiation doses (lx h) while the colour changes equalled for higher doses. In addition, the overall patterns of wood colour changes were observed to be similar for both types of LED lamps. Therefore, only one type of LED lamps $(3000 \mathrm{~K})$ was included in the irradiation experiments for establishing the main changes in wood due to exposure to LEDs.

\subsection{Discolouration}

As it can be seen from Figure 2, the total exposure doses used in the irradiation experiments of both irradiation types were sufficient to reach plateau in discolouration only for UM ash while still progressing colour changes were observed for other specimens suggesting that higher irradiation doses should be applied to assess the total possible discolouration. Nevertheless, during the irradiation experiments with both radiation sources (UV and LED), colour changes of all specimens exceeded $2 \Delta$ Eab units, which is recognized to be the limit of human perception to notice difference between two colours [35]. 


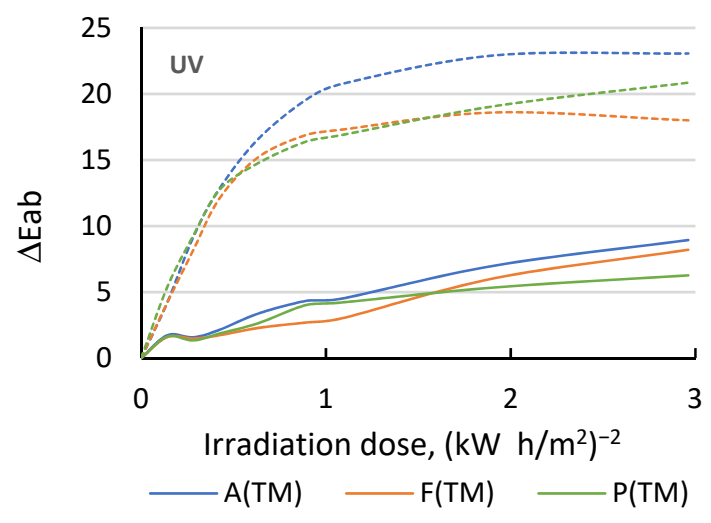

(a)

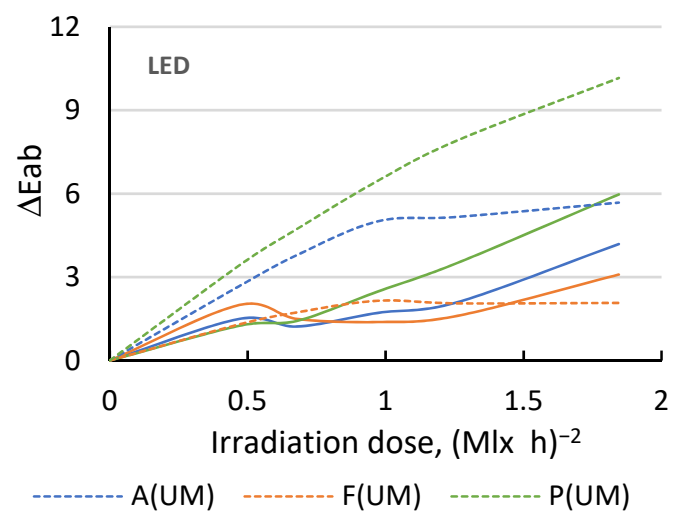

(b)

Figure 2. Discolouration of unmodified (UM) and thermally modified (TM) aspen (A), ash (F), and pine (P) wood due to exposure to UV radiation (a) and LED lamps (b).

The rate of discolouration significantly varied for wood types (UM and TM) and species. In general, for both irradiation types, slower rate of discolouration and consequently lower colour change at the end of both exposure experiments were detected for TM aspen and pine wood compared to their UM counterparts. These results support the outcome of the research in which improvement of colour stability of wood due to the thermal modification was observed [6,31,36]. It is suggested that better colour stability of TM wood is due to transformations in lignin during TM process [6,31]. Regarding ash wood, improved colour stability of TM wood was found only for the effect of UV radiation. Different trend was observed for ash wood exposed to LED lamps for which similar discolouration for UM and TM wood was detected with even slightly higher colour change of TM specimens at the end of the experiment. The differences in discolouration rate between UM and TM wood generally were substantially smaller in the case of LED lamps emitting only visible light than UV radiation. It suggests that thermal modification imparts less improvement in colour stability to visible light than to UV radiation.

Comparing colour changes of the studied species, the results differ depending on the irradiation type. Greater effect of LED lamps was on pine and the smaller on ash discolouration for both UM and TM wood. However, really substantial differences between species were observed only for UM wood. The general patterns of changes in colour parameters $\mathrm{L}^{*}, \mathrm{a} * \mathrm{~b} *$ (not shown) also were quite similar for all TM species while significant differences between species were found in the case of UM wood. Similarly, discolouration due to UV exposure was observed to be quite alike for TM wood and varying in the case of UM wood. The common effect of UV for both wood types was the greater colour changes for aspen wood.

\subsection{Reflectance Difference Spectra}

Reflectance difference spectra are used in the present study to compare pattern of the changes in wood surface appearance due to exposure to UV and LED. However, it should be mentioned that discolouration of wood due to photodegradation is not a uniform process. The newly developed colour may change in a course of irradiation not only in intensity but also in hue due to changes in the involved wavelength regions [25]. Consequently, different trends in reflectance difference spectra may be observed for different discolouration stages. Therefore, the difference reflectance spectra for approximately equal $\Delta$ Eab units assessed in the discolouration experiments are used for comparison of changes in hue due to photodegradation caused by different radiation sources. Figure 3 represents the difference spectra for discolouration of around $4 \Delta$ Eab units with exception of UM ash exposed to LED, for which the discolouration at the end of the experiment had only reached $2 \Delta$ Eab units. 


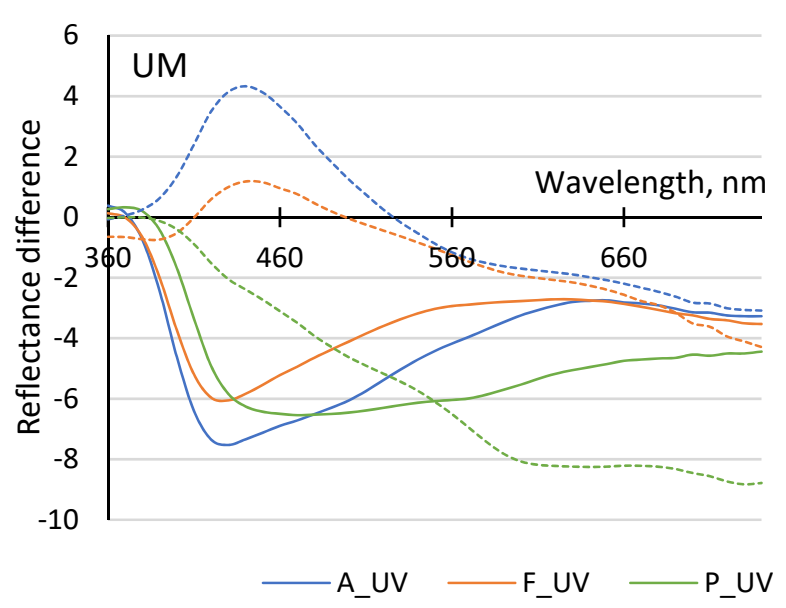

(a)

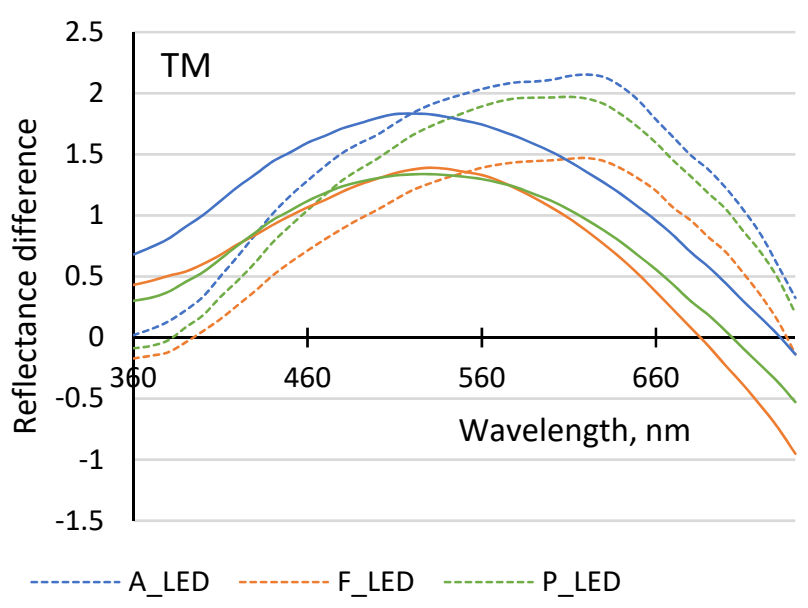

(b)

Figure 3. Reflectance difference spectra of unmodified (a) and thermally modified (b) of aspen (A), ash (F), and pine (P) due to exposure to UV radiation and LED lamps.

It can be seen that the exposure to irradiation caused increase in reflectance of TM wood (Figure $3 b$ ) in almost the whole wavelength range of visible light indicating on intensive reduction in chromophores. On the contrary, decrease in reflectance was mostly characteristic for UM wood (Figure 3a) implying that formation of new chromophores had prevailed in the process of discolouration. The dominant wavelength region of reflectance changes also differs for TM and UM wood with the region of the shorter wavelengths being more transformed for UM wood. In general, the changes in reflectance caused by exposure to UV and LED were of quite similar trend for TM wood of all three species. However, hardly any changes in the shorter wavelength region and red-shifted region of the major changes (from $520 \mathrm{~nm}$ for UV to $620 \mathrm{~nm}$ for LED) are well seen for TM wood of all species exposed to LED lamps indicating that exposure to UV and LED irradiation does not cause equal transformations in TM wood chromophoric system. Consequently, the colour alteration of TM wood due to irradiation may impart somewhat different hue to wood depending on the light source. More multi-shaped changes in reflectance were detected for UM wood both between the species and depending on the irradiation source. Generally, reflectance changes of UM wood of all species exposed to UV are quite similar with a common trend of a pronounced reduction in reflectance in the wavelength region between 400 and $500 \mathrm{~nm}$ which could be attributed to the formation of quinoidal structures [25]. However, significant differences can be observed when effect of two radiation types on UM wood is compared. The observed differences between changes in reflectance of UM specimens caused by UV radiation and LED lamps emitting mainly visible light agrees with the findings that the changes in colour parameters depend on the wavelength of the incident radiation $[20,21]$. Various patterns of colour parameter changes were detected for a number of wood species in experiment simulating indoor sunlight exposure with a xenon-arc lamp equipped with a window glass filter [37]. The results of the present study demonstrate that in case of UM wood even more significant differences between species were caused by visible light (LED) than UV radiation. The changes in reflectance clearly show that differences in hue of the new colour developed due to irradiation of UM wood depend more on the light source than in the case of TM wood.

\subsection{FTIR Spectra}

FTIR spectra have been well found to be powerful tool extensively used for evaluation of chemical changes in functional groups of wood due to photodegradation [12,25,26,35,38,39]. FTIR-ATR spectra of specimens before (control) and after exposure to UV radiation and LED lamps are depicted in Figure 4. 

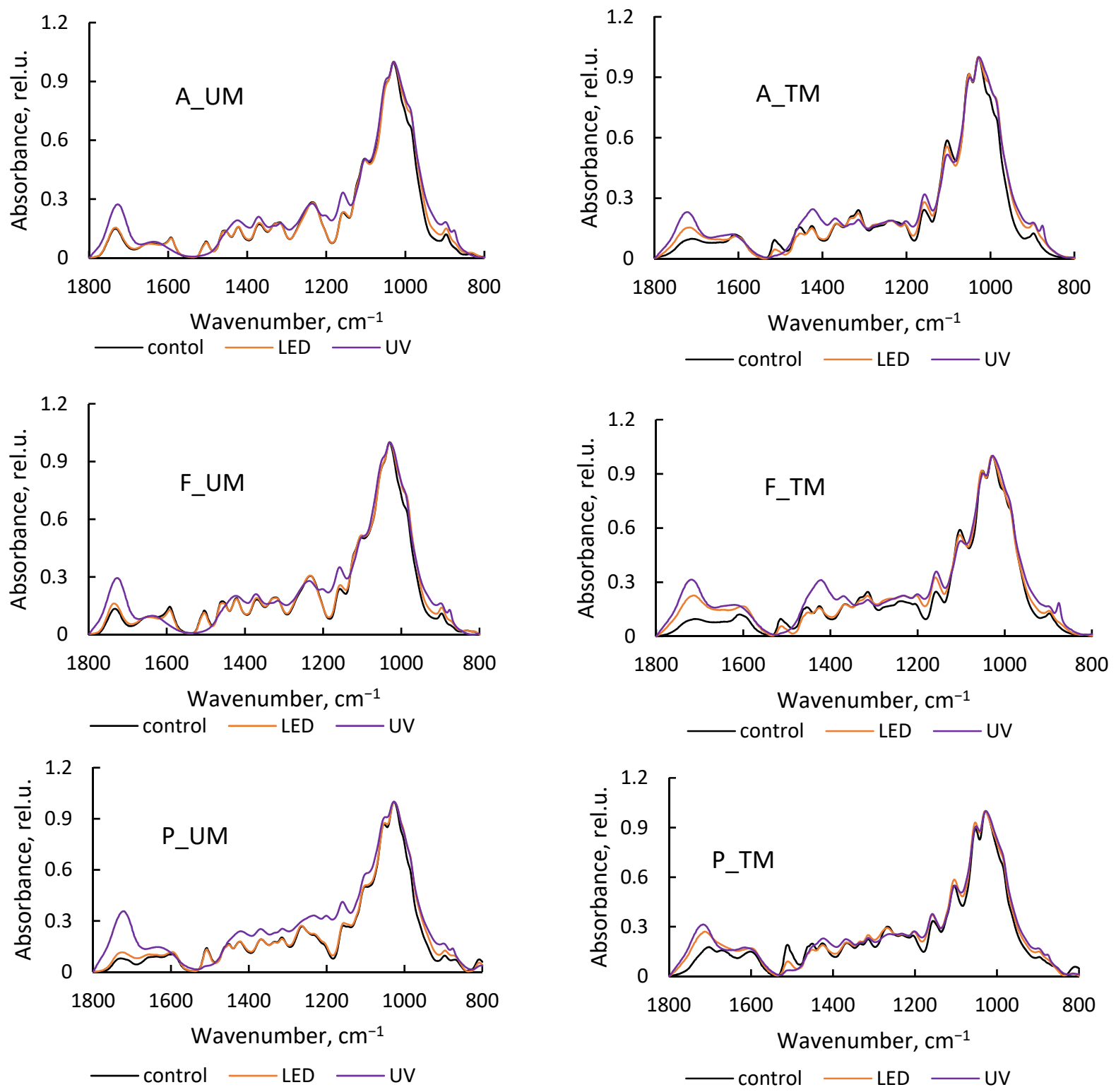

Figure 4. FTIR-ATR spectra of unmodified (UM) and thermally modified (TM) of aspen (A), ash (F), and pine (P) before (control) and after exposure to UV radiation and LED lamps.

It can be seen, that for the applied irradiation doses only UV radiation caused significant changes in absorption intensities of UM wood while both sources of radiation exerted definite influence on the absorption intensities of TM wood. In case of UM wood exposed to LED lamps, the only detected change was a slight increase in absorption in a band around $1730 \mathrm{~cm}^{-1}$ signalling about increase in carbonyl groups while notable changes in bands associated with degradation of lignin were not observed. Comparing the magnitudes of discolouration due to LED irradiation, greater colour change was detected for UM than TM aspen and pine specimens at the end of exposure (Figure 2). Correlation between change in colour and FTIR intensities has been observed in other studies [24,38]. Considerable involvement of extractives in discolouration of UM wood exposed to LED lamps emitting almost merely visible light could be the explanation of the different result detected in the present study. It is recognised that structural changes in extractives cannot be highlighted by FTIR due to their low content [40]. In general, major changes in absorption spectra were observed in the same bands for TM wood irradiated with both radiation sources as well as for UM wood exposed to UV radiation. This agrees with the findings of other 
research that photodegradation causes changes in similar functional groups for UM and TM wood $[9,12,41]$. Overall, the most prominent changes in absorption intensity were an increase in the bands around $1730 \mathrm{~cm}^{-1}$ (unconjugated carbonyl groups) and $1160 \mathrm{~cm}^{-1}$ (carbohydrates) accompanied by a decrease in the bands associated with lignin around $1510 \mathrm{~cm}^{-1}, 1460 \mathrm{~cm}^{-1}$. In addition to these bands, decrease in the band around $1600 \mathrm{~cm}^{-1}$, which is associated with syringyl units in lignin [12,40], was observed for UM aspen and ash. These results well agree with findings of other research $[25,35,41]$.

\subsection{Formation of Water-Soluble Substances}

It has long been known that exposure of wood to solar irradiation leads to the formation of low molecular weight water-soluble photodegradation products [42,43]. To evaluate the potential formation of the water-soluble components during wood interior exploitation, extractive-free wood was exposed to irradiation followed by extraction with hot water.

Comparing wood degradation caused by UV irradiation, formation of considerably more extractives was found for UM wood than TM wood (Table 1). For both types of wood, the content of extractives detected in wood after UV irradiation varied between species with a similar trend of higher content detected for aspen while similar contents found for ash and pine. In the case of exposure to LED lamps, quite similar quantities of extractives were formed in wood of both types. The exception was UM pine, for which significantly more extractives were detected compared with all other specimens, which could be due to the higher sensitivity of guaiacyl lignin to photodegradation [44]. Both discolouration and formation of extractives are the result of wood photodegradation. However, no correlation was detected for either of wood types between the amount of soluble components and wood colour change due to exposure to both irradiation types. It indicates that discolouration alone cannot provide complete information on severity of wood photodegradation.

Table 1. Content of water-soluble components in unmodified (UM) and thermally modified (TM) wood formed due to exposure to UV and LED lamps and pH of extracts.

\begin{tabular}{cccccc}
\hline \multirow{2}{*}{ Wood Type } & \multirow{2}{*}{ Species } & \multicolumn{2}{c}{ Extractives, $\%$} & \multicolumn{2}{c}{ pH } \\
\cline { 2 - 6 } & & UV & LED & UV & LED \\
\hline \multirow{3}{*}{ UM } & Aspen & 27.4 & 2.2 & 3.5 & 5.2 \\
\cline { 2 - 6 } & Ash & 21.0 & 2.4 & 3.6 & 5.5 \\
\cline { 2 - 6 } & Pine & 20.3 & 6.2 & 3.7 & 4.7 \\
\hline \multirow{2}{*}{ TM } & Aspen & 15.6 & 3.0 & 3.7 & 4.5 \\
& Ash & 12.7 & 2.3 & 3.5 & 4.3 \\
& Pine & 12.5 & 1.1 & 3.7 & 4.1 \\
\hline
\end{tabular}

Typically, $\mathrm{pH}$ values of extracts differed between irradiation sources while they were similar for wood types and species exposed to the same source of irradiation. Lower $\mathrm{pH}$ values were found for extracts of wood exposed to UV irradiation suggesting more carbonic acids generated in these specimens. UV-Vis absorption spectra of the water extracts are shown in Figure 5.

Quite uniform UV-Vis absorption spectra, which were characterized by continuous absorption throughout the UV region and negligible absorption in the visible light region above $400 \mathrm{~nm}$, were obtained for all extracts. For both types of wood and both irradiation sources, the most intense absorption was observed in the far-UV region around $205 \mathrm{~nm}$ and more or less pronounced shoulders or broad bands around $230 \mathrm{~nm}, 250 \mathrm{~nm}$ and $280 \mathrm{~nm}$. The bands around $205 \mathrm{~nm}, 230 \mathrm{~nm}$ and $280 \mathrm{~nm}$ could be due to low molecular weight lignin degradation products, while the shoulder around $250 \mathrm{~nm}$ could be related to carbohydrate degradation products $[45,46]$. Comparing spectra of extracts after UV and LED irradiation, the most obvious differences are the absence of clearly visible band around 
$280 \mathrm{~nm}$ for specimens exposed to LED lamps and pronounced shoulder around $250 \mathrm{~nm}$ for specimens exposed to UV of both UM and TM wood of all species. It could be related with more solubilized degradation products originating from wood carbohydrates due to UV irradiation resulting in overlapping of the bands around 250 and $280 \mathrm{~nm}$. Similar transformation of the band around $280 \mathrm{~nm}$ into pronounced shoulder for longer exposure times to UV radiation has been depicted in research about surface degradation of yellow pine [42]. The results, which indicate the solubilisation of both lignin and carbohydrates, agree with the finding about chemical composition of weathered wood demonstrating the major loss in lignin which was accompanied by lower losses in hemicelluloses and only marginal cellulose losses [43]. However, for more detailed information about soluble degradation products formed due to photodegradation other methods such as liquid chromatography or pyrolysis-gas chromatography-mass spectrometry (Py-GC/MS) should be usednot.

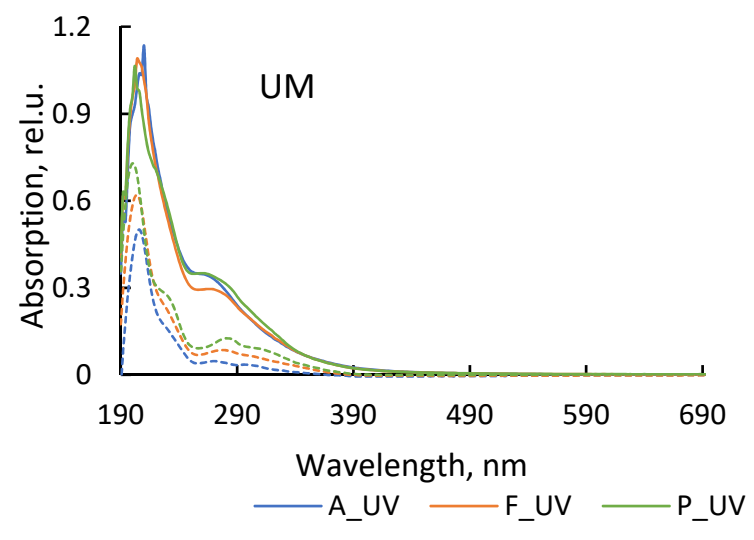

(a)

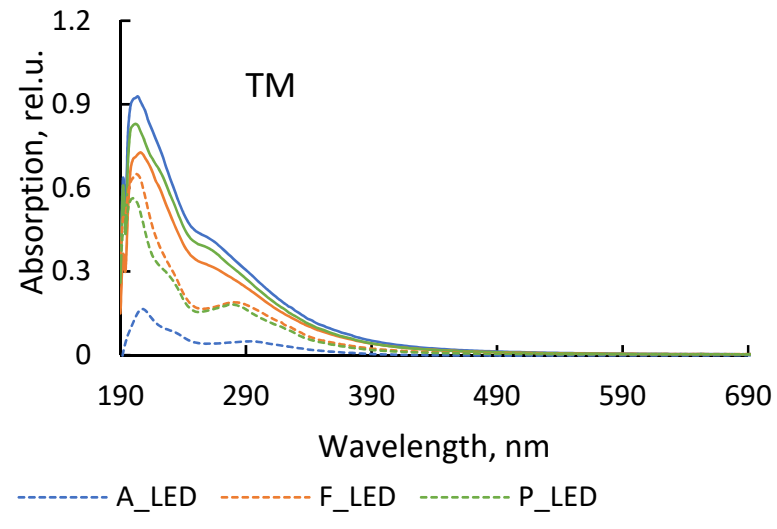

(b)

Figure 5. UV-Vis absorption spectra of water extracts of unmodified (UM) (a) and thermally modified (TM) (b) aspen (A), ash (F), and pine (P) wood exposed to UV and LED lamps.

\section{Conclusions}

Both types of radiation (UV and LED lamps) caused visually perceptible discolouration of TM and UM wood. In general, slower rate and less variations in colour change among species were detected for TM wood compared to UM wood. However, this trend was less pronounced for wood exposed to the LED lamps when even higher discolouration was found for TM ash compared to its UM counterpart at the end of the experiment.

Comparing chemical changes, inconsistent results were obtained by analysing changes in FTIR spectra and formation of water-soluble components. Significant changes in FTIR spectra were observed for TM wood exposed to both UV and LED irradiation while only insignificant changes were found for UM wood exposed to LED lamps. Nevertheless, similar content of water-soluble components was formed in both TM and UM wood exposed to LED lamps. Significantly more extractives were formed under the influence of UV radiation in UM wood than TM wood suggesting that UV causes more severe photodegradation in UM wood.

Author Contributions: Conceptualization, D.C. and E.K.; methodology, D.C.; formal analysis, E.K.; investigation, M.K.; writing—original draft preparation, D.C.; writing-review and editing, E.K. and I.A.; supervision, B.A.; funding acquisition, D.C. All authors have read and agreed to the published version of the manuscript.

Funding: This research was funded by the Latvian Council of Science, Project Number lzp-2020/20174 "Effect of Different Artificial Lightings on Wood Surface Photodegradation".

Institutional Review Board Statement: Not applicable.

Informed Consent Statement: Not applicable. 
Data Availability Statement: The data presented in this study are available on request from the corresponding author.

Conflicts of Interest: The authors declare no conflict of interest.

\section{References}

1. Hill, C.A.S. Thermal Modification of wood. In Wood Modification: Chemical, Thermal, and Other Processes; John Willey and Sons Ltd.: Chichester, UK, 2006; pp. 99-127. [CrossRef]

2. Militz, H.; Altgen, M. Processes and properties of thermally modified wood manufactured in Europe. In Deterioration and Protection of Sustainable Biomaterials; ACS Symposium Series; ACS Publications: Washington, DC, USA, 2014; Volume 1158, pp. 269-285. [CrossRef]

3. Ormondroyd, G.; Spear, M.; Curling, S. Modified wood: Review of efficacy and service life testing. Constr. Mater. 2015, 168, 187-203. [CrossRef]

4. Jirouš-Rajković, V.; Miklečić, J. Weathering resistance of modified wood-A review. Annu. Croat. Acad. Eng. 2018, 10, 223-244.

5. Hill, C.; Altgen, M.; Rautkari, L. Thermal modification of wood-A review: Chemical changes and hygroscopicity. J. Mater. Sci. 2021, 56, 6581-6614. [CrossRef]

6. Ayadi, N.; Lejeune, F.; Charrier, F.; Charrier, B.; Merlin, A. Color stability of heat-treated wood during artificial weathering. Eur. J. Wood Wood Prod. 2003, 61, 221-226. [CrossRef]

7. Esteves, B.; Marques, A.; Domingos, I.; Pereira, H. Heat-induced colour changes of pine (Pinus pinaster) and eucalypt (Eucalyptus globulus) wood. Wood Sci. Technol. 2008, 42, 369-384. [CrossRef]

8. Chen, Y.; Gao, J.; Fan, Y.; Tshabalala, M.A.; Stark, N.M. Heat-Induced Chemical and Color Changes of Extractive-Free Black Locust (Robinia Pseudoacacia) Wood. BioResources 2012, 7, 2236-2248. [CrossRef]

9. Miklečić, J.; Jirouš-Rajković, V.; Antonović, A.; Španić, N. Discolouration of thermally modified wood during simulated indoor sunlight exposure. BioResources 2011, 6, 434-446. [CrossRef]

10. Nhacila, F.; Sitoe, E.; Uetimane, E.; Manhica, A.; Egas, A.; Möttönen, V. Effects of thermal modification on physical and mechanical properties of Mozambican Brachystegia spiciformis and Julbernardia globiflora wood. Eur. J. Wood Wood Prod. 2020, 78, 871-878. [CrossRef]

11. Esteves, B.; Pereira, H. Wood modification by heat treatment: A review. BioResources 2009, 4, 370-404. [CrossRef]

12. Xing, D.; Wang, S.; Li, J. Effect of Artificial Weathering on the Properties of Industrial-Scale Thermally Modified Wood. BioResources 2015, 10, 8238-8252. [CrossRef]

13. Sandberg, D.; Kutnar, A.; Mantanis, G. Wood modification technologies-A review. iForest Biogeosci. For. 2017, 10, 895-908. [CrossRef]

14. Hon, D.N.S. Weathering and photochemistry. In Wood and Cellulosic Chemistry; Hon, D.N., Shiraishi, N., Eds.; Marcel Dekker: New York, NY, USA, 2001; pp. 513-546.

15. Baysal, E.; Degirmentepe, S.; Şimşek, H. Some surface properties of thermally modified scots pine after artificial weathering. Maderas. Cienc. Tecnol. 2014, 16, 355-364. [CrossRef]

16. Jirouš-Rajković, V.; Miklečić, J. Heat-Treated Wood as a Substrate for Coatings, Weathering of Heat-Treated Wood, and Coating Performance on Heat-Treated Wood. Adv. Mater. Sci. Eng. 2019, 2019, 8621486. [CrossRef]

17. Chen, Y.; Fan, Y.; Gao, J.; Stark, N.M. The effect of heat treatment on the chemical and color change of black locust (Robinia pseudoacacia) wood flour. BioResources 2012, 7, 1157-1170. [CrossRef]

18. Bekhta, P.; Niemz, P. Effect of High Temperature on the Change in Color, Dimensional Stability and Mechanical Properties of Spruce Wood. Holzforschung 2003, 57, 539-546. [CrossRef]

19. Sundqvist, B.; Morén, T. The influence of wood polymers and extractives on wood colour induced by hydrothermal treatment. Eur. J. Wood Wood Prod. 2002, 60, 375-376. [CrossRef]

20. Kataoka, Y.; Kiguchi, M.; Williams, R.S.; Evans, P.D. Violet light causes photodegradation of wood beyond the zone affected by ultraviolet radiation. Holzforschung 2007, 61, 23-27. [CrossRef]

21. Živković, V.; Arnold, M.; Radmanović, K.; Richter, K.; Turkulin, H. Spectral sensitivity in the photodegradation of fir wood (Abies alba Mill.) surfaces: Colour changes in natural weathering. Wood Sci. Technol. 2013, 48, 239-252. [CrossRef]

22. Cīrule, D.; Meija-Feldmane, A.; Kuka, E.; Andersons, B.; Kurnosova, N.; Antons, A.; Tuherm, H. Spectral Sensitivity of Thermally Modified and Unmodified Wood. BioResources 2015, 11, 324-335. [CrossRef]

23. George, B.; Suttie, E.; Merlin, A.; Deglise, X. Photodegradation and photostabilisation of wood-The state of the art. Polym. Degrad. Stab. 2005, 88, 268-274. [CrossRef]

24. Pandey, K.K. Study of the effect of photo-irradiation on the surface chemistry of wood. Polym. Degrad. Stab. 2005, 90, 9-20. [CrossRef]

25. Pandey, K.K.; Vuorinen, T. Comparative study of photodegradation of wood by a UV laser and a xenon light source. Polym. Degrad. Stab. 2008, 93, 2138-2146. [CrossRef]

26. Srinivasa, K.; Pandey, K.K. Photodegradation of thermally modified wood. J. Photochem. Photobiol. B Biol. 2012, 117, 140-145. [CrossRef] [PubMed]

27. Zahri, S.; Belloncle, C.; Charrier, F.; Pardon, P.; Quideau, S. UV light impact on ellagitannins and wood surface colour of European oak (Quercus petraea and Quercus robur). Appl. Surf. Sci. 2007, 253, 4985-4989. [CrossRef] 
28. Chang, T.-C.; Chang, H.-T.; Wu, C.-L.; Chang, S.-T. Influences of extractives on the photodegradation of wood. Polym. Degrad. Stab. 2010, 95, 516-521. [CrossRef]

29. Baar, J.; Wimmer, R.; D'Amico, S. Dependence of colour and discolouration on total extractive content of African Padauk and Jatoba. Wood Sci. Technol. 2014, 48, 1155-1165. [CrossRef]

30. Chang, T.-C.; Chang, S.-T. Multiple photostabilization actions of heartwood extract from Acacia confusa. Wood Sci. Technol. 2017, 51, 1133-1153. [CrossRef]

31. Deka, M.; Humar, M.; Rep, G.; Kričej, B.; Šentjurc, M.; Petrič, M. Effects of UV light irradiation on colour stability of thermally modified, copper ethanolamine treated and non-modified wood: EPR and DRIFT spectroscopic studies. Wood Sci. Technol. 2008, 42, 5-20. [CrossRef]

32. Esteves, B.M.; Herrera, R.; Santos, J.; Carvalho, L.; Nunes, L.; Ferreira, J.; Domingos, I.J.; Cruz-Lopes, L. Artificial weathering of heat-treated pines from the Iberian peninsula. BioResources 2020, 15, 9642-9655. [CrossRef]

33. Huang, X.; Kocaefe, D.; Kocaefe, Y.; Boluk, Y.; Pichette, A. A spectrocolorimetric and chemical study on color modification of heat-treated wood during artificial weathering. Appl. Surf. Sci. 2012, 258, 5360-5369. [CrossRef]

34. Timar, M.C.; Varodi, A.M.; Gurau, L. Comparative study of photodegradation of six wood species after short-time UV exposure. Wood Sci. Technol. 2016, 50, 135-163. [CrossRef]

35. Mokrzycki, W.S.; Tatol, M. Colour difference DE-A survey. Mach. Graph. Vis. 2011, 20, 383-411.

36. Deka, M.; Petrič, M. Photo-degradation of water borne acrylic coated modified and non-modified wood during artificial light exposure. BioResources 2008, 3, 346-362. [CrossRef]

37. Oltean, L.; Teischinger, A.; Hansmann, C. Wood surface discolouration due to simulated indoor sunlight exposure. Eur. J. Wood Wood Prod. 2007, 66, 51-56. [CrossRef]

38. Cogulet, A.; Blanchet, P.; Landry, V. Wood degradation under UV irradiation: A lignin characterization. J. Photochem. Photobiol. B Biol. 2016, 158, 184-191. [CrossRef] [PubMed]

39. Lu, Y.; Lu, Y.-C.; Hu, H.-Q.; Xie, F.-J.; Wei, X.-Y.; Fan, X. Structural Characterization of Lignin and Its Degradation Products with Spectroscopic Methods. J. Spectrosc. 2017, 2017, 8951658. [CrossRef]

40. Tolvaj, L.; Molnár, Z.; Németh, R. Photodegradation of wood at elevated temperature: Infrared spectroscopic study. J. Photochem. Photobiol. B Biol. 2013, 121, 32-36. [CrossRef]

41. Yildiz, S.; Tomak, E.D.; Yildiz, U.C.; Ustaomer, D. Effect of artificial weathering on the properties of heat treated wood. Polym. Degrad. Stab. 2013, 98, 1419-1427. [CrossRef]

42. Hon, D.N.-S.; Chang, S.-T. Surface degradation of wood by ultraviolet light. J. Polym. Sci. Polym. Chem. Ed. 1984, $22,2227-2241$. [CrossRef]

43. Evans, P.D.; Michell, A.J.; Schmalzl, K.J. Studies of the degradation and protection of wood surfaces. Wood Sci. Technol. 1992, 26, 151-163. [CrossRef]

44. Colom, X.; Carrillo-Navarrete, F.; Nogués, F.; Garriga, P. Structural analysis of photodegraded wood by means of FTIR spectroscopy. Polym. Degrad. Stab. 2003, 80, 543-549. [CrossRef]

45. Chang, H.-T.; Su, Y.-C.; Chang, S.-T. Studies on photostability of butyrylated, milled wood lignin using spectroscopic analyses. Polym. Degrad. Stab. 2006, 91, 816-822. [CrossRef]

46. Tribulová, T.; Kačík, F.; Evtuguin, D.; Čabalová, I. Assessment of chromophores in chemically treated and aged wood by Uv-Vis diffuse reflectance spectroscopy. Cellul. Chem.Technol. 2016, 50, 659-667. 